\title{
Dynamic visualisation and modelling to support sustainable phosphate management
}

\author{
J.P. Isaacs ${ }^{1 *}$, R.E. Falconer ${ }^{2}$, D.J. Gilmour ${ }^{3}$ and D.J. Blackwood ${ }^{3}$ \\ ${ }^{1}$ School of Computing \& Engineering Systems, University of Abertay, Dundee, UK \\ ${ }^{2}$ SIMBIOS, University of Abertay, Dundee, UK \\ ${ }^{3}$ School of Contemporary Sciences, University of Abertay, Dundee, UK \\ *Email: j.Isaacs@abertay.ac.uk
}

\begin{abstract}
Under the WFD the UK water companies are responsible for providing effective treatment methods which will reduce the level of phosphate, a key nutrient in river eutrophication, in their respective waterways. The selection of effective treatment methods poses a sustainability problem as there are a number of economic and social aspects which must be balanced with the environmental standards set down by the WFD. This choice becomes even more complex as all of the stakeholders involved, the companies, the local government, local industry and the general public must be engaged in the decision-making process if they are to fully support whatever solution is chosen. This paper describes a sustainability assessment and visualisation toolkit, PhiZ, which has been designed to allow the assessment and communication of the sustainability of phosphate management scenarios. The PhiZ system takes the approach of combining a number of computational models covering the economic, social and environmental aspects of the scenarios with a unique visualisation based on $3 \mathrm{D}$ rendering techniques derived from the computer games industry, through which the results of the models can be communicated. This unique visualisation not only allows the ecological state of the river to be assessed over time but also allows a non-expert user to interactively investigate the impact of different management techniques on sustainability of the river catchment. PhiZ does not define sustainability but does provide a method for all the stakeholders involved to compare the relative sustainability of a number of management scenarios.
\end{abstract}

\section{Introduction}

Under the Water Framework Directive the UK water companies are responsible for providing effective treatment methods which will reduce the level of phosphate, a key nutrient in river eutrophication, in their respective waterways. The sustainability assessment of any treatment method or management option adopted for the control of river phosphate is an extremely complex issue. This complexity derives from the fact that any assessment must draw criteria from the three aspects of sustainability (Figure 1) (Sahota and Jeffrey, 2005) to ensure an effective and efficient service, maintain public health and welfare and reduce resource usage (Foxon et al., 2002)

It is also clear that this process is made even more difficult by the need to include a diverse range of stakeholders in the decision-making process when these management options are planned. To be effective, the decision-making process is dependent on all the stakeholders being genuinely involved, but the current prevailing practice is for decisionmakers to seek agreement for proposals once the key decisions have been made (Geldof, 2005). Involving all the stakeholders presents a major challenge. Communicating the sustainability in general and its implication for the decisionmaking process is extremely difficult due to the inherent complexity of the data involved. Coupled with this, for any decision to be truly sustainable, all stakeholders must be able to understanding the short and long term implications of alternative courses of action (Beierle and Cayford, 2002).

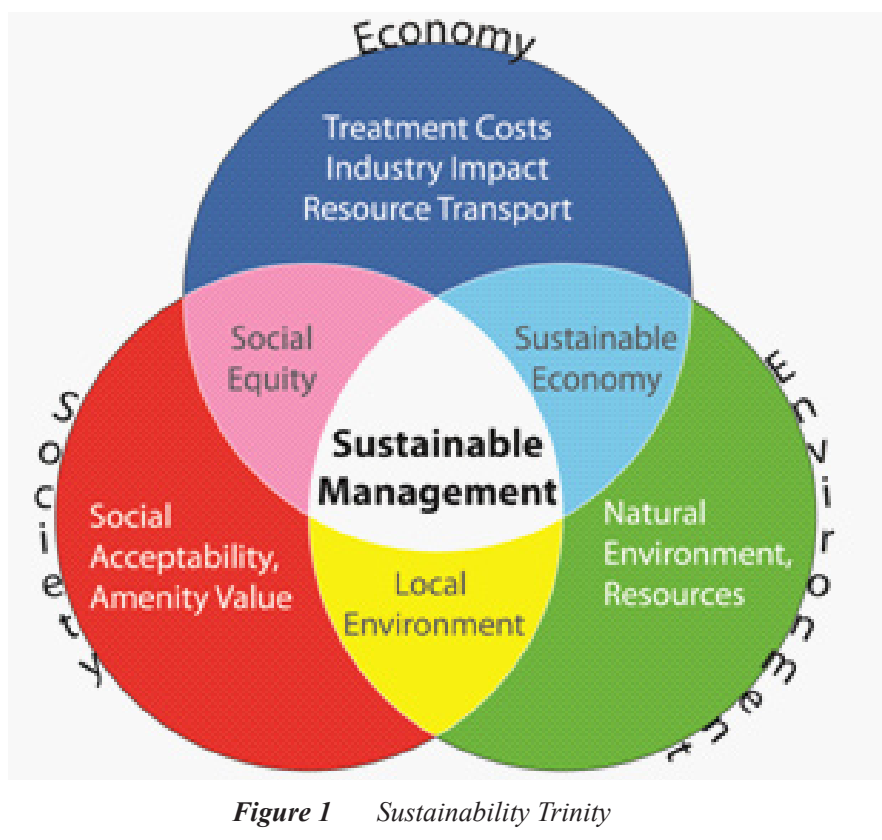

Kapelan et al. (2005) suggest that this communication barrier can be overcome through the use of $3 \mathrm{D}$ visualisation. It is suggested that using $3 \mathrm{D}$ visualisation will enable more effective communication between experts and non-experts and thus allow the inclusion of a wider range of stakeholders. This view that visualisation aids stakeholder 
involvement in the decision-making process has been reinforced by a number of other studies (Ball et al., 2007; Miller et al., 2008b; Hamilton, 2005; Hamilton et al., 2001; Salter et al., 2009; Gill et al., 2010; Wu et al., 2010; Bishop and Stock, 2010) where visualisation has been used in public consultation for a variety of planning decisions. However, all of these examples concentrate on the physical appearance of the decision being made and were not designed to confer any quantitative information to the stakeholders.

GIS (Geographic Information Systems)have been used to provide the quantitative information in a graphical way, providing the user with an interactive data-exploring interface which allows them to overlay a number of different maps onto a 2D surface and then to conduct complex geospatial analysis (Salter et al., 2009). However, it has been shown (Lowe, 2004; Lowe, 2003) that many nonexpert stakeholders have great difficulty in deciphering and understanding scientific displays and maps. Due to its complexity and high learning curve, GIS requires the user "to think like a geographic information scientist" (Clarke, 2001) and is still considered to be a difficult-to-use, expert tool (Traynor and Williams, 1995). Its use in decision-making has made it difficult for non-expert stakeholders, especially the general public, to participate fully in planning decisions (Salter et al., 2009; Al-Kodmany, 2002).

People develop the ability to navigate and visually process 3D representations on a subconscious level throughout their lives (Charters et al., 2002b), allowing users to quickly recognise the spatial context of the decision (Danahy et al., 1999). This subconscious ability suggests that the user will not have to work to visualise the consequences of the management options, but can concentrate on the decision being made. Other visualisation systems used in decision-making include CAD-based systems and specialised 3D commercial tools such as Autodesk Revit, ArchiCAD and other 3D CAD drafting environments. The information visualisation and immersive capabilities of these packages are currently limited as they are primarily designed for rendering high quality static images (Drettakis et al., 2007). 3D GIS has attempted to solve some of these issues but still remains a complex expert orientated tool which is designed primarily to show existing data and, as such, it can appear sluggish due to the large volume of data involved; adding a 3D layer only compounds this and prevents realtime visualisation (Ranzinger and Gleixner, 1997).

Modern computer games are able to provide the user with possible, fantasy or realistic environments with a large degree of interaction, especially over the control of the view or camera with which the user sees the environment. The authors believe that the use of games techniques in $3 \mathrm{D}$ visualisation may help the lack of participation and interactivity available in current visualisation methods such as CAD and GIS and may allow for greater realism of the environments being displayed. Game engines are modular code libraries which handle input, output (3D rendering, 2D drawing, sound), and generic physics/dynamics for game worlds, written for a specific game but general enough to be used for a family of similar games. PhiZ uses a bespoke rendering engine (SAVE Engine) designed to closely link underlying scientific data with a realistic virtual environment while maintaining real-time interaction.

\section{PhiZ methodology}

As can be seen from Figure 2, the Phiz System is formed from four main components, Geospatial Data, Sustainability Indicators, the INCA P model and the SAVE Engine. These components and how they are combined are described in the following section.

\section{Geospatial data}

Geospatial data from a number of sources can be used to recreate the appearance of the real environment being studied. This includes: digital terrain models (DTM) and digital elevation models (DEM), commonly sourced from LIDAR or satellite data; aerial photography, usually from satellite data, but also from organisational photograph repositories; and GIS files. These datasets are combined using computer game rendering technologies to form a realistic representation of the environment.

These data come in an array of different formats, structures, scales and resolutions. Some of the datasets can be extremely large in terms of file size and memory usage,

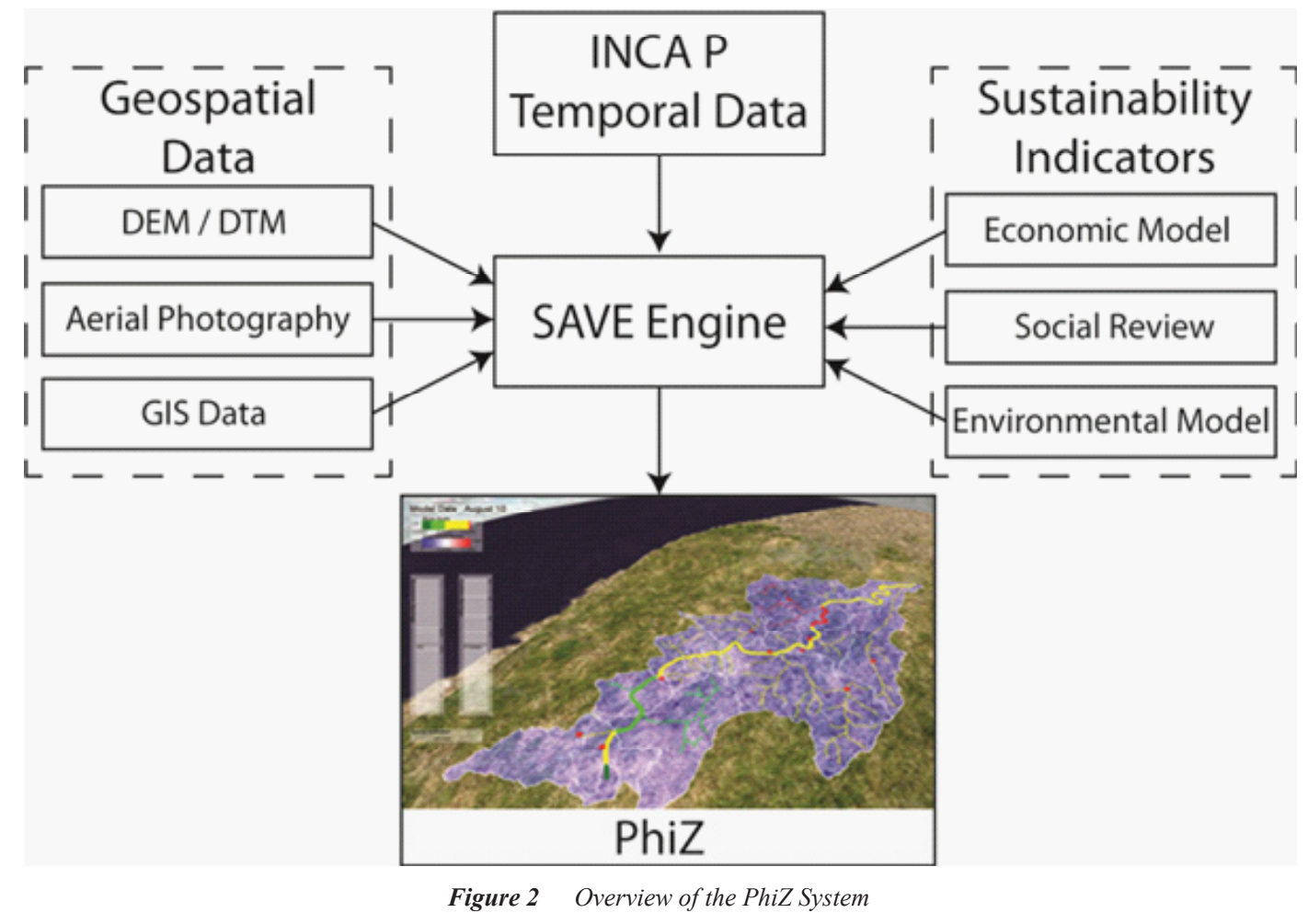


especially aerial photography and high detail DEMs. The challenge lies in combining all these data and ensuring real time interactivity and overcoming the interaction problems in existing GIS systems.

\section{Sustainability indicators}

It is recognised that there is need to select criteria and indicators that are appropriate and relevant to the context of a sustainability assessment and this approach has been adopted here. A small set of indicators was selected, guided by the body of knowledge above and the experience of the research team and based closely on the specification for the research project. The selected indicators are discussed in more detail below.

\section{Economic indicators}

A number of economic factors were required to establish a lifecycle management conceptual model, taking account of a range of management options including source control, change in fertiliser use and phosphorus removal within WwTW. Consequently net present value (NPV) costs, mostly calculated on a per capita basis were required for:

- Iron dosing at WwTW for phosphorus reduction in effluents

- Construction of BNR for phosphorus reduction in effluents

- Source control of phosphorus to WwTW (including tap water dosing, removal of phosphorus from food additives and detergents)

- Replacing the use of inorganic fertilisers with biosolids

- Infrastructure costs (pipe replacement and new/upgraded treatment works)

- Overall treatment costs

Full details of the economic model used are available in the UKWIR report (UKWIR, 2011).

\section{Environmental Indicators}

As with the economic indicators, a range of management options were investigated to determine their carbon impact, i.e $\mathrm{CO}_{2}$ arising from the introduction of a particular option. Consequently carbon costs or savings were calculated for:

- Construction of new treatment plants or infrastructure

- Lead pipe replacement

- Replacement of imported fertilisers

- Reduction of $\mathrm{P}$ addition and removal

The data used by the carbon model were sourced from UKWIR and Atkins Global; full detail of the carbon based environmental model is available in the UKWIR report (UKWIR, 2011).

\section{Social indicators}

A range of potential social indicators were identified in the literature on sustainability studies of wastewater and solid waste treatment and disposal options. A common feature of these studies was that whilst social indictors were identified, they were not evaluated in quantitative terms due to the methodological difficulties in the measurement of social phenomenon. The indicators addressed social aspects at a range of levels including local impacts that might be measurable, such and noise and smell, and wider issues such social equity and environmental justice. Balkema et al. (2002) provided a comprehensive review of indictors for sustainability assessment of wastewater systems and the category of indictors that they provide is appropriate to the context of this study, where the scenarios cover a range of individual, corporate and institutional stakeholders. These are:
- Awareness/participation

- Competence/information requirements of stakeholders

- Cultural acceptance

- Institutional requirements

\section{INCA P}

The Integrated Catchments Model for Phosphorous (INCA $\mathrm{P}$ ) is a process-based, mass balance model that simulates the phosphorus dynamics in both the plant/soil system and the stream. Using a semi-distributed representation, INCAP simulates the variations in phosphorus resulting from different land use types within a river system. The model thus allows the impact of different land management and wastewater treatment practices on the phosphate levels in the catchment to be determined. The land phase of INCA-P includes a simplified representation of direct runoff, soil water and groundwater flows, and the soil processes that involve phosphorus, to simulate organic and inorganic phosphorus concentrations. In addition, the model includes a multi-reach in-stream component that routes water down the main river channel simulating total phosphorus (dissolved plus particulate phosphorus) concentrations in the water. INCA produces daily estimates of the phosphate soli and instream levels along with a number of other in-stream factors INCA such as soluble reactive phosphorus concentrations (determined from the total phosphorus), macrophyte and epiphyte populations, algal biomasses, sediment size and flow rate (Whitehead et al., 1998, Wade et al., 2002).

\section{The SAVE Engine}

The SAVE (Sustainability Assessment, Visualisation and Enhancement) Engine, written in C\# and XNA, is a custom designed rendering engine based on contemporary computer games and rendering techniques. The engine has been designed to provide virtual environments which closely couple a realistic representation of the real world with underlying scientific models whilst still providing the user with a real time interactive experience (Isaacs et al., 2011a, Isaacs et al., 2011b).

The SAVE Engine allows real world to be accurately represented through the incorporation of geospatially indexed datasets such as GIS files, satellite images, digital elevation models (DEMS) and maps (GB Ordinance Survey). The engine then uses specialised graphical techniques (High Level Shaders) to render all of these components and into a recognisable representation of the environment being studied. As the engine is developed using computer game technologies, it maintains the highest possible degree of user interaction allowing the user complete control over how the environment is viewed.

The SAVE engine's purpose is not simply to display a representation of the environment and provide access to the underlying models but to display the results of the underlying models to the user in a meaningful way. This is achieved by using a number of visualisation techniques which enable the INCA P data, and the sustainability models to be viewed together over time.

\section{Wensum case study application}

The varied nature of river catchments precludes modelling and evaluation of scenarios on a typical catchment and therefore the approach taken was to illustrate the application of the toolkit on one catchment, allowing conclusions to be drawn on the scenarios in the context of that catchment and to 
explore any generic issues that might arise from the exemplar application. The Wensum catchment was selected for the purpose of the case study, to represent a mixed catchment with a variety of land use, point and diffuse source inputs of phosphorus.

A baseline scenario was established based on the current AMP4 operation of the treatment works in the catchment. Three possible management options, in consultation with the water authorities, were then identified, namely, the achievement of a $40 \%$ reduction in P output from the works through the introduction of a wide range of source control measures, in place of P removal systems; the widespread removal of phosphates at the works using iron dosing with AMP 5 investments; and the combination of source control with the replacement of two existing works by a modern BNR treatment process. Additionally, the effect of increasing the amounts of bio solids to agriculture to $50 \%$ in each management option was considered. In summary, the baseline plus six scenarios were modelled and compared using the sustainability assessment and visualisation toolkit. These were:

Scenario 1: (Baseline)

Scenario 2: Baseline Plus 40\% Source Control.

Scenario 3: Baseline plus 40\% Source Control, 50\% Biosolids.

Scenario 4: AMP5.

Scenario 5: AMP5 plus 50\% Biosolids.

Scenario 6: BNR plus 40\% Source Control.

Scenario 7: BNR plus 40\% Source Control, 50\% Biosolids.

To determine the scenarios' effectiveness at reducing the phosphate levels, the current baseline situation and the impact of each scenario on the phosphate level was modelled using the INCA-P modelling system. Sustainability indicator values were also calculated from the baseline for each scenario, based on the criteria stated on the previous section. This gave each scenario an INCA P value and the range of sustainability indictors.

A range of techniques exist to combine such data; these can be categorised as weighted aggregation methods to reduce the data set to a single comparative indicator or outranking, or preference-based methods that produce a rank order of options. In both cases, whilst the decisionmaker is presented with a more readily understood measure of sustainability, the rich information conveyed to the decision-maker is lost. Furthermore, the phosphate's life cycle is subject to temporal variation and therefore a dynamic approach to sustainability assessment and communication is required. This sustainability analysis was undertaken using the PhiZ system. This produced a dynamic visualisation of each of the scenarios at the same time, whilst displaying each of the measured indictors with the discourse on social indictors along with the INCA P value which thus allowed the comparison of the scenarios.

\section{Communicating sustainable management options}

Combining the sustainability indicators with INCA model output over time creates an overall dataset of over 1.5 million data points, which would be extremely difficult to comprehend using traditional means even for the expert stakeholders involved. Using the PhiZ visualisation system this data set was transformed into a much simpler representation of the rivers' water quality. Figure 3 shows how the sustainability indicators, the INCA P datasets and the geospatial data have been combined into a single virtual

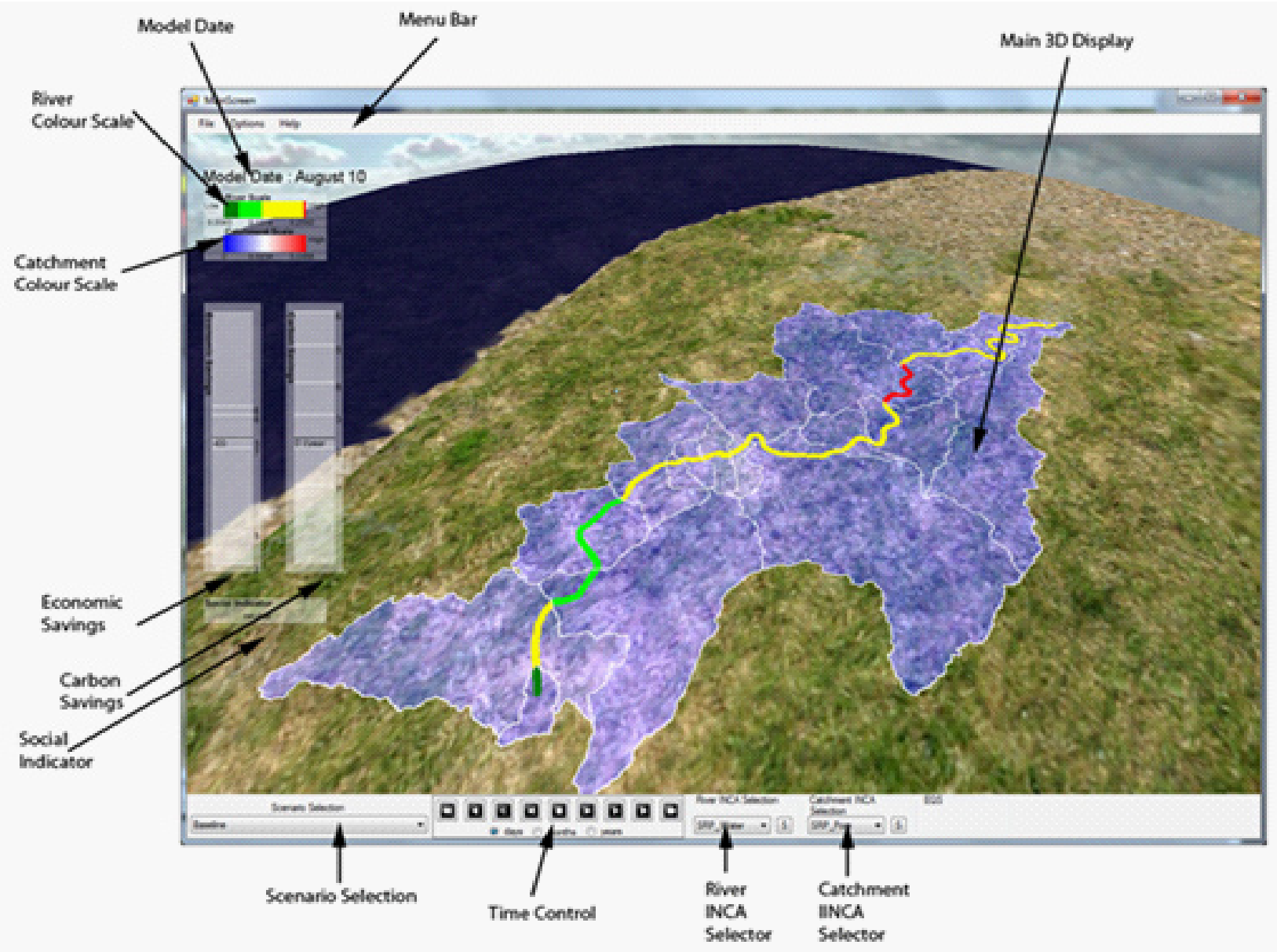

Figure 3 The PhiZ user interface. 


\section{Excellent Good Moderate Poor}

Figure 4 Colours used to represent the EQS on the river

environment.

The main 3D display shows the virtual representation of the river catchment and surrounding area. The spatial and temporally variable INCA output can be viewed and compared for each scenario. A colour scale is used to represent the environmental quality standard (EQS, Figure 4) and thus show where the phosphate level exceeds that permitted.

The economic, carbon savings graphs show the level of economic and carbon savings the selected scenario provides, they also show the difference positive (savings) or negative (costs) each management option provides. The social indicator box provides an explanation of the social issues associated with this particular management option.

The model date indicator displays the current day in the INCA model run being shown on the 3D display. The stakeholders are able to move forward or backward in time using the time control, to determine if specific river reaches or treatments works have a greater impact during different seasons.

The most important aspect of the PhiZ system is its ability to indicate, visually, the consequences of the choices the user makes. Figure 5 shows the application of the PhiZ system to the six scenarios chosen on the Wensum catchment. The PhiZ system runs the scenarios concurrently, enabling the user to flip between the scenarios and identify the impact of that particular management option, both in terms of the phosphate level, via INCA P, but also in the sustainability of that option.

\section{Conclusions}

As the PhiZ system was developed in conjunction with a UKWIR research report, there was the opportunity to test the visualisation outputs at a number of project steering groups meetings and the project completion meeting. This allowed the usefulness of the system to be tested directly in aiding the discussion and rationalisation of phosphate

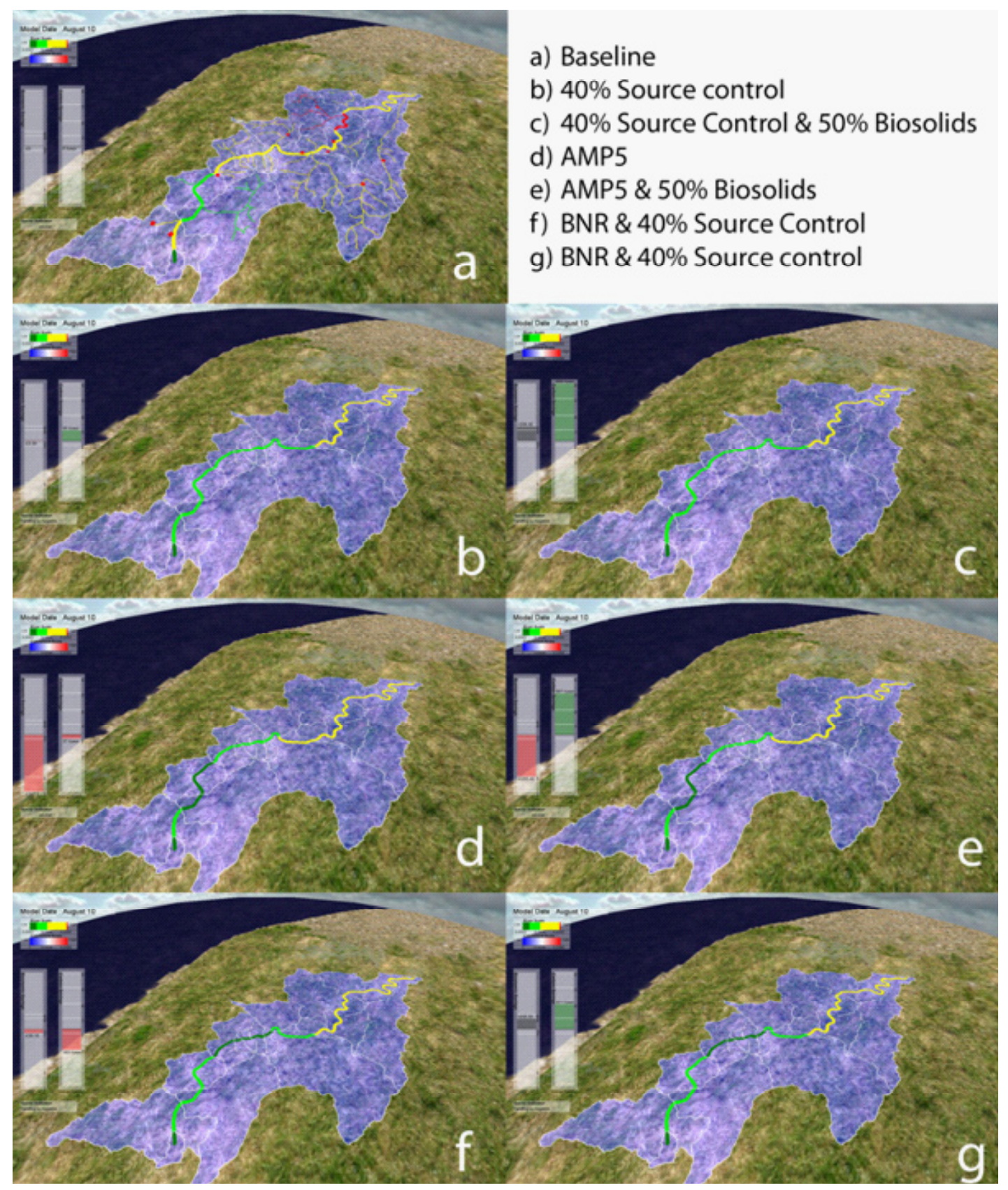

Figure 5 PhiZ Application to case study scenarios. 
management decisions. The visualisation was well received by the members of the steering group who believed that the system would be successful in demonstrating the complex facets of sustainable management decisions. As a result of the steering group meetings, the PhiZ system was included on CD as an appendix to the final project report (UKWIR, 2011). The report also recommended that the tool should be widely demonstrated and developed to take account of further sustainability issues and combined with other tools and data to create a sustainable planning tool for the whole water industry. Tests of the virtual environment and the colour scales used have also been performed with various expert and non-expert focus groups to determine the range of values which can be identified. Preliminary results of these focus group tests show widespread acceptance of the use of virtual environments and also that most users have the ability to identify data differences of about $2 \%$ between the scenarios. The focus group tests and steering group meetings also showed that the tool provoked discussion about the issues surrounding the management options. The steering group members were also able to identify anomalies and dramatic occurrences in the data.

The SAVE engine has been developed to allow its application to any virtual environment based problem. As Phiz has been developed on this platform it would be possible to apply the assessment strategy to any river catchment once the INCA P data and sustainability information had been collected. Traditional methods such as graphs, tables, maps and GIS systems are essential in allowing expert decisionmakers to perform their duties. However, the problem arises when this information has to be communicated to other stakeholders, experts in other fields or high level decisionmakers. If the consequences of the decision or the underlying concepts are not fully understood by the person making the decision or those the decision is going to affect, clearly the sustainability of the decision cannot be guaranteed. Using 3D visualisation, coupled with accurate modelling, allows this barrier to be reduced, allowing all the stakeholders to speak a common language and influence the decision regardless of their expertise or background.

\section{References}

Al-Kodmany, K. 2002. Visualization tools and methods in community planning: from freehand sketches to virtual reality. J. Plann. Literature, 17, 189. Ashley, R.M.,

Blackwood, D., Butler, D. and Jowitt, P. 2004. Sustainable water services: a procedural guide. Sustainable Water Industry Asset Resources Decisions Project, London: IWA Publishing.

Balkema, A.J., Preisig, H.A., Otterpohl, R. and Lambert, F.J.D. 2002. Indicators for the sustainability assessment of wastewater treatment systems. Urban water, 4,153-161.

Ball, J., Capanni, N. and Watt, S. 2007 Virtual reality for mutual understanding in landscape planning. Development, 2005, 2.

Beierle, T.C. and Cayford, J. 2002. Democracy in practice: Public participation in environmental decisions. Resources for the Future.

Bishop, I.D. and Stock, C. 2010. Using collaborative virtual environments to plan wind energy installations. Renewable Energy, 35, 2348-2355.

Clarke, K.C. 2001. Getting started with geographic information systems. Prentice Hall, Upper Saddle River, NJ. USA.

Danahy, J., Spiller, R. and Verlag, W. 1999. Visualization data needs in urban environmental planning and design. Photogram.Week, 351, 356.
Drettakis, G., Roussou, M., Reche, A. and Tsingos, N. 2007. Design and evaluation of a real-world virtual environment for architecture and urban planning. Presence: Teleoperators \& Virtual Environments, 16, 318-332.

Foxon, T., McIlkenny, G., Gilmour, D., Oltean-Dumbrava, C., Souter, N., Ashley, R., Butler, D., Pearson, P., Jowitt, P. and Moir, J. 2002. Sustainability criteria for decision support in the UK water industry. J. Environ. Plan. Manage., 45, 285-301.

Geldof, G.D. 2005. Integrated water management and complexity. Coping with complexity in integrated water management. On the road to interactive implementation. Tauw, Deventer.

Gill, L., Kumar, V., Lange, E., Lerner, D. and Morgan, E. 2010. An interactive visual decision support tool for sustainable urban river corridor management. Computer.

Hamilton, A. 2005 Urban information model for city planning. City, 10 (April),55-67.

Hamilton, A., Trodd, N., Zhang, X., Fernando, T. and Watson, K. 2001. Learning through visual systems to enhance the urban planning process. Environ. Plan. B: Planning and Design, 28, 833-845.

Isaacs, J.P., et al. 2011. Enhancing urban sustainability using $3 \mathrm{D}$ visualisation. Proceedings of the ICE - Urban Design and Planning. 164(3): pp.163-173.

Isaacs, J.P. et al. 2011. Immersive and non immersive 3D virtual city: decision support tool for urban sustainability. J. Inform. Technol. Construction 16: Special Issue: Use of Gaming Technology in Architecture, Engineering and Construction, 149-159.

Kapelan, Zoran, Savic, D. and Walters, G. 2005. Decisionsupport tools for sustainable urban development. Eng. Sustainab., 158, 135-142.

Lowe, R. 2003. Animation and learning: selective processing of information in dynamic graphics. Learning Instruct., 13, $157-176$.

Lowe, R. 2004. Interrogation of a dynamic visualization during learning. Learning Instruct., 14, 257-274.

Miller, D., Horne, P., Morrice, J., Ball, J. and Messager, P. 2008. Participatory strategic planning using a virtual reality environment. In: Proc. GISRUK, 367-371.

Ranzinger, M. and Gleixner, G. 1997. GIS datasets for 3D urban planning. Comput., Environ. Urban Systems, 21, 159-173.

Sahota, P.S. and Jeffrey, P. 2005. Decision-support tools: moving beyond a technical orientation. Proc. ICE Engineering Sustainability, 158, 127-134.

Salter, J.D., Campbell, C., Journeay, M. and Sheppard, S.R.J. 2009. The digital workshop: exploring the use of interactive and immersive visualisation tools in participatory planning. J. Environ. Manage., 90, 2090-101.

Traynor, C. and Williams, M.G. 1995. Why are geographic information systems hard to use? In: $\mathrm{CHI}$ '95: Conference companion on human factors in computing systems. New York, NY, USA: ACM, 288-289.

UKWIR 2008. Final Report: Source control of phosphorus from domestic sources - Options and Impacts.

UKWIR 2011. Final Report: Phosphorous lifecycle management.

Wu, H., He, Z. and Gong, J. 2010. A virtual globe-based $3 \mathrm{D}$ visualization and interactive framework for public participation in urban planning processes. Comput. Environ. Urban Syst., 1-8.

Wade, A.J., Hornberger, G.M., Whitehead, P.G., Jarvie, H.P. and Flynn, N. 2001. On modeling the mechanisms that control in-stream phosphorus, macrophyte, and epiphyte dynamics: An assessment of a new model using general sensitivity analysis. Water Resour. Res., 37, 2777-2792. 